\title{
A Post-Tenure Review System That Is Good Personnel Policy: Is It Possible?
}

Michael C. Seeborg, (E-mail: mseeborg@titan.iwu.edu), Illinois Wesleyan University Gerald Olson, (E-mail: golson@titan.iwu.edu), Illinois Wesleyan University

\begin{abstract}
The recent implementation of post-tenure review programs at many American universities is an interesting and controversial trend. Some of these systems are "developmental" and unthreatening while others are "summative" and can lead to the dismissal of under-performing faculty members. This paper argues that because of the unique nature of academic labor markets, summative review systems may not be appropriate for most universities. By weakening the institution of tenure, summative post-tenure review systems decrease academic freedom. They also reduce efficiency within universities by discouraging collegiality and collaboration. We propose that universities in need of systems of post-tenure review establish "developmental" programs that do not threaten academic freedom or weaken the institution of tenure. These systems give faculty members a chance to critically evaluate past performance and motivate them to develop professionally. A developmental post-tenure review system recently adopted at Illinois Wesleyan University is presented as an example.
\end{abstract}

\section{Introduction}

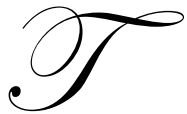

he calls for greater accountability of tenured faculty members have been increasing over the past decade and, in response, many state legislatures and university governing boards have implemented summative post-tenure review programs (Licata, 1997). Supporters of post-tenure review programs often argue that such programs are necessary to assure a productive and engaged senior faculty and, when necessary, to weed out the "deadwood." They frequently point to the non-academic private sector where regular evaluations of senior workers result in rewards for good performance and punishments for sub par performance. They ask, why should senior faculty members be exempt from the type of scrutiny given to professionals in industry?

Typical of the arguments for a summative form of post-tenure review is found in this statement made at an interview by Stanley Koplik, former Chancellor of the Massachusetts Board of Higher Education:

It's important to monitor faculty performance throughout their career. Yes, getting tenure is an exhausting process, and the road to tenure has worked well. But we must also ask ourselves, 'If tenure is such a sturdy, rigorous process that extracts the best from an individual, what happens in the post-tenure years? Is there a decline in productivity? The results are mixed. If the tenure-review process is right and appropriate in the first place, why not continue it in some form throughout the life of the faculty member?.... Trustees want a post-tenure system with teeth - one that includes dismissal for non-performers....You can adhere to due process and be fair. An honest review process will reveal that some faculty should be dismissed. (Trower, 1999, p. 28).

Like Koplik, most arguments in favor of summative post-tenure review call for greater accountability of tenured faculty. The basis of these arguments is that greater accountability will lead to increased faculty productivity and will encourage faculty more closely align their own activities with the missions of the university.

Readers with comments or questions are encouraged to contact the authors via email. 
On the other side of the debate is The American Association of University Professors (AAUP), which has long opposed post-tenure review. In 1983 the AAUP adopted the following position on post-tenure review.

The Association believes that periodic formal institutional evaluation of each post probationary faculty member would bring scant benefit, would incur unacceptable costs, not only in money and time but also in dampening of creativity and of collegial relationships, and would threaten academic freedom. The Association emphasizes that no procedure for evaluation of faculty should be used to weaken or undermine the principles of academic freedom and tenure. The Association cautions particularly against allowing any general system of evaluation to be used as grounds for dismissal or other disciplinary sanctions. (AAUP, 1983).

Despite such expressions of concern by professional organizations like the AAUP, American colleges and universities are fast implementing post-tenure review programs. Recognizing the futility in trying to stop the movement altogether, the AAUP has more recently adopted the position that they would provide standards of good practice for post-tenure review. If it is necessary for a university to adopt post-tenure review, the program should focus on faculty development rather than be a reevaluation of tenure. In addition, the AAUP states that any system of post-tenure review should be faculty developed and should protect academic freedom. (AAUP, 1998).

To date, no standard for post-tenure review has emerged. Programs range from extremely summative programs where unfavorable reviews can result in financial penalties or termination to developmental programs that are consistent with AAUP standards (Licata, 1997).

This paper argues that because of the unique nature of academic labor markets, corporate models of evaluation of senior employees may not be appropriate for most universities. These summative systems of review threaten the institution of tenure, decrease academic freedom, and reduce efficiency within universities by discouraging collegiality and collaboration. Instead, universities that need to develop systems of post-tenure review should consider "developmental" programs that do not threaten academic freedom or weaken the institution of tenure.

The next section examines a faculty designed post-tenure review program recently adopted at Illinois Wesleyan University (IWU) that is decidedly developmental focus. After a brief description of the IWU program, we turn to a consideration of the relationship of post-tenure review on the institution of tenure. We show that summative plans that threaten tenure also can have adverse effects on academic freedom, labor efficiency, and morale. We then argue that developmental post-tenure review plans, such as that adopted at IWU, do not suffer from these shortcomings.

\section{The Illinois Wesleyan University Post-Tenure Review Program}

In November 1999, Provost Janet McNew asked a faculty task force to design a program of post-tenure review for the university that was consistent with its liberal arts traditions and the campus culture. After considerable discussion and research on practices at other universities, the task force determined that an acceptable post-tenure review program would have to:

- $\quad$ Be developmental rather than summative

- Be flexible enough to respond to the diverse professional development needs of faculty members

- $\quad$ Be supported by sufficient resources to assure meaningful faculty development

- Involve peers in the review process

- $\quad$ Produce meaningful feedback to the faculty member under review

- $\quad$ Not interfere with academic freedom, and

- $\quad$ Not be overly burdensome.

The task force spent time soliciting ideas from the faculty through surveys, open forums, and a spirited exchange of ideas on the university intranet. The debate was often intense and continued for several months. Although this process of dialog between the task force and faculty members was time consuming, it helped us to refine the proposal and develop a consensus. Finally, in January 2001, the faculty approved the plan by a large margin. 
The IWU plan is unique because of its emphasis on faculty development and its rejection of the summative model advocated by many. Unlike many existing systems of post-tenure review, the outcome of the review process cannot be dismissal or disciplinary action. Furthermore, faculty peers, rather than administrators, are the main participants in the review process.

Here is a brief outline of the IWU post-tenure review process. (Illinois Wesleyan University Post-tenure Review Task Force, 2001). To facilitate our discussion, let us suppose that a hypothetical faculty member, named Professor Smith, is to undergo the review process. What can Professor Smith expect?

First, Professor Smith can expect to undergo a review every five to seven years. This flexibility may permit Smith to have her review about two years before her anticipated sabbatical leave. This will facilitate planning for the leave.

Second, Professor Smith selects an Individual Review and Development Committee. The committee consists of Smith and at least two tenured faculty members. The faculty member can choose not to include his or her supervisor on the committee.

Third, Professor Smith works intensely with the Individual Review and Development Committee. This work involves wide-ranging informal discussions of her professional development. These discussions would review teaching, service, and scholarship over the past several years, and identify professional development goals. The Individual Review and Development Committee's work is critical to the success of the program. After members of the committee review past performance, they turn their attention to the future. According to the IWU Post-Tenure Review Task Force, the planning phase of their work is extremely important. For example, the committee members should explore the following question:

... what would the faculty member like to accomplish over the next several years and how can the academic community help realize this vision? During this phase of the discussion, the two invited committee colleagues should both listen sympathetically and respond critically to the faculty member's ideas and plans and 'brainstorm' with him or her about the possible. Then members may assist in distilling the vision into a new course with new pedagogy; an article or research experiment or artistic creation or performance that tests new ground in its subject or interpretation; a reconsidered approach to university service that emphasizes quality by appealing to the faculty member's individual gifts. (Illinois Wesleyan University Post-Tenure Review Task Force, 2001)

Fourth, after the series of meetings with the Individual Review and Development Committee, Professor Smith prepares a written professional development plan and a two-page summary of that plan. The two-page summary includes an abstract of the complete plan and a proposal for faculty development resources. Smith submits copies of the summary form with his academic department, the program administrator (Associate Dean), and the Provost's Office. The retrospective and possibly self-critical written professional development plan becomes the personal property of the faculty member and is not part of any official personnel file. Thus, the program assures some accountability through the filing of summary forms without dampening candid and critical reflections that may be included in the more lengthy development plan document.

Finally, Professor Smith receives in-kind or monetary support of $\$ 5,000$ or a course release after completing the review. She spells out the intended use of the resources in the two-page summary form mentioned above. The main idea of the resource award is to provide a wide range of resources to advance faculty development and to provide tangible encouragement for faculty members to take the review process seriously. Some possible uses of the development resources include paying for a course release, buying research equipment, funding professional travel, or paying for a stipend to support research or course development. Smith is required submit a brief report to the Associate Dean explaining how her resources were used.

Having described the details of the Illinois Wesleyan University post-tenure review program, lets consider how the proposed post-tenure review program might affect Smith's professional behavior. Will it motivate her to 
work harder and be more productive? Will it increase collegiality between Smith and peers? How will it affect Smith's relationship with supervisors?

The most unusual, and perhaps controversial, aspect of this post-tenure review program is the degree of autonomy that Smith has over her own review process. The program gives Smith the authority to select her own peer review committee and to draft his own development plan. She might even choose not to include her immediate supervisor on the post-tenure review committee. We believe that this autonomy is a good thing. It insures that Smith has the potential to choose a committee that can best assist with her professional development.

Another unique aspect of the Illinois Wesleyan University post-tenure review program is the guarantee of an equal amount of professional development support to every faculty member that completes the review. There are three main reasons for opting for a uniform award for all. First, since every Individual Review and Development Committee is different, there is no effective way of comparing review outcomes committees. Second, since a major purpose of the post-tenure review is to encourage peer collegiality, it makes little sense to pit Smith against colleagues in competition for resources. Third, Smith will be more honest and earnest in the review process when she knows that a candid evaluation of weaknesses will not result in penalties of any kind.

Finally, the Illinois Wesleyan post-tenure review plan is unique in that it does not link directly with summative personnel decisions like promotion, salary determination, or even dismissal for cause. Not linking posttenure review directly to the competitive reward structure gives Smith an incentive to evaluate weaknesses candidly and to develop a plan for professional improvement. We believe that Smith would be less candid about weaknesses under a more summative post-tenure review system where unfavorable reviews could result in an unfavorable merit pay increment or remedial action. Moreover, if the process threatened his status as a tenured faculty member, Smith would certainly not voluntarily reveal shortcomings.

The next section develops the important relationship between post-tenure review and the institution of tenure. We show that developmental post-tenure review programs like the one adopted at Illinois Wesleyan University reinforce the positive aspects of tenure systems. Conversely, summative post-tenure review programs weaken tenure, and, in the process, threaten academic freedom, decrease efficiency and hurt motivation.

\section{Does Post-tenure Review Weaken the Institution of Tenure?}

Most external appeals for post-tenure review systems advocate the type of summative evaluations that are typical in corporate America. Following this particular corporate model, university administrators would intensely evaluate the performance of tenured faculty members on a regular schedule. Suppose that the review reveals problems in the performance of our hypothetical Professor Adam Smith. Typically, administrators prescribe remedial programs to try to bring him up to speed. If Smith does not shape up, they initiate dismissal for cause proceedings.

Advocates of summative reviews certainly would find the type of developmental review program adopted at Illinois Wesleyan University lacking. From their prospective, these developmental programs mistakenly reverse traditional hierarchical lines of authority, putting Smith in charge of his own review and improperly reduce the role of the immediate supervisor.

Proponents of summative reviews also argue that developmental type programs lack accountability. For example, they probably would complain that the Illinois Wesleyan University program does not punish Smith for poor performance, but instead gives him the same level of development resources as it gives to high performers. They would ask, why not hold Smith to the same level of accountability as corporations hold their senior employees?

Our answer is that universities should not subject tenured faculty members to corporate style summative reviews because these reviews weaken the institution of tenure. By weakening tenure, summative reviews will likely cause both a decrease in academic freedom and a decrease in economic efficiency. We examine arguments for these two claims in the following paragraphs. 


\section{Academic Freedom and Post-Tenure Review}

Academic freedom is a cherished value in most colleges and universities. In his eloquent 1964 defense of tenure, noted economist Fritz Machlup argues,

.... all the disadvantages of a strict tenure system, whether they are borne by the institutions, by the individual teachers, or by the entire academic profession, are outweighed by one important advantage, accruing chiefly to society at large. This one advantage - really the only justification for the system of academic tenure - lies in the social products of academic freedom, which in many situations ...can be guaranteed only by the instrument of tenure. The various disadvantages, serious as they may be, are parts of the cost which society must incur in order to secure the great benefit of academic freedom and of the fruits it bears. (Machlup, p. 22).

In his defense of tenure, Machlup (1996) recognizes that there are some professors that work hard through the probationary period, secure tenure, and then rest on their laurels. He concludes, "it must be granted that the tenure system may contribute to some deterioration in the performance of some professors and, consequently, may harm the institutions which are stuck with the retrograde members of the faculty." (p. 15). However, Machlup believes that the number in this group is relatively small. Universities can continue to motivate tenured faculty through development programs, tangible awards for performance and an intellectually stimulating academic environment. It is our belief that a developmental post-tenure review program like the one adopted at Illinois Wesleyan University will provide significant peer and resource encouragement to tenured faculty needing a boost.

To serve society to the fullest extent possible, Professor Smith and his colleagues must be free to advance new ideas and be critical of accepted theories, public policies, and social institutions, including his own university (Machlup, p. 23). When Smith challenges conventional wisdom, or is critical of his own institution, he is likely to encounter resistance, and may experience more difficulty in a summative type post-tenure review than his more complacent and conforming counterparts.

However, it is the academic nonconformists, like Smith, who produce the greatest benefits for society at large. They change paradigms and they invent. They also encourage their students to think critically and be positive agents for change. Thus, maintaining the academic freedom of tenured faculty members has important implications for society because it fosters the development of new ideas and promotes social activism (McPherson and Schapiro, 1999, p. 93). Summative periodic review programs, on the other hand, would most likely stymie the nonconventional creative impulses of many professors.

Another argument made by those who would weaken tenure by implementing summative post-tenure review programs is that a weaker tenure system does not threaten academic freedom because of other protections, especially the First Amendment. While it is true that the First Amendment does provide some free speech protection for professors, it does not insure continued employment. After an examination of recent court cases Finkin (1996) concludes that, "putting aside the fact that the First Amendment is inapplicable to private institutions, the argument rests on the assumption that the First Amendment is coextensive with academic freedom. It is not." (Finkin, p. 191) In the absence of the protection of academic freedom that comes with tenure, administrators would generally have little trouble finding cause to dismiss nonconformists.

For these reasons, we believe summative post-tenure review systems will decrease academic freedom. However, a developmental post-tenure review of the type adopted at Illinois Wesleyan University would not threaten academic freedom because developmental reviews encourage the free exchange of ideas without the threat of dismissal.

In addition to the academic freedom argument, there are three principle ways that summative post-tenure reviews weaken the efficiency of academic markets. First, they are unlikely to motivate professors because of the absence of hierarchical career ladders. Second, because of the specialized knowledge that professors bring to the job, summative evaluation by administrators with little specific knowledge of the discipline is problematic. Third, 
periodic summative reviews are likely to reduce faculty morale. By putting faculty in competition with one another, they discourage professional collaboration and collegiality. The remainder of the paper elaborates on these arguments and shows that it is better to implement a developmental system of post-tenure review rather than a summative system.

\section{An Internal Labor Market Argument against Summative Reviews}

In recent years, a number of economists have considered the economic rational for tenure (McPherson and Winston, 1993; and McPherson and Schapiro, 1999), often coaching their arguments in terms of internal labor markets. We apply the same line of reasoning here to argue against weakening tenure with summative post-tenure review.

Most corporate internal labor markets, where summative periodic reviews are common, are fundamentally different from academic labor markets for professors. A typical corporation has a number of internal labor markets for its professional workers (Osterman, 1994). A stylized internal labor market consists of an entry-level position (i.e., port of entry) and a well-defined career path. Hiring takes place in entry level occupations with positions up the career ladder filled through internal promotions. Rules and procedures determine who is eligible to move from one job classification to the next. (Osterman, 1984, p. 2) In this type of job market, employees acquire many "firm specific" skills on the job. As they acquire these skills, they become qualified for the next job on the career ladder. With promotion to a new occupational classification comes an increase in pay and an opportunity to continue to acquire a new set of job specific skills and, in time, to seek yet another promotion. This process of skill acquisition and promotion may repeat itself many times as the corporate professional moves up the career ladder.

Continuous evaluation by supervisors is critical to determine who moves from one classification to the next and when the promotion is to occur. In some cases workers move from one career path to another, say from a computer programming career track to a management career ladder, in response to discoveries of new aptitudes and talents. Supervisors, who are usually further up the career ladder, are in a good position to evaluate their subordinates. In this type of internal labor market, it makes sense to invest a significant amount of time and resources in periodic summative performance reviews. Frequent periodic reviews give the firm the opportunity to make rational marginal adjustments in rewards and assignments to reflect the skills, aptitudes, and performance of the worker.

Contrast this job market to that faced by Professor Smith, who was just hired to fill a new tenure-track position in history. Smith, with $\mathrm{PhD}$ in hand, has a specialty in early American history and feels ready to meet his new department's need in that area. Smith will be replacing the university's only early American historian who just retired. Unlike his private sector counterpart in computer programming, Smith comes to the university knowing more than most of his colleagues--perhaps more than all of his colleagues--about his field of specialization. He has proven his research skills through a rigorous $\mathrm{PhD}$ program. Now he faces a demanding probationary period of seven years to demonstrate that he can be a productive scholar, an excellent teacher and give service to the university. Weakening the traditional tenure systems by implementing periodic summative post-tenure reviews makes little sense.

Unlike most professional workers in the corporate sector, Smith does not face a long career ladder. In fact, he does not face a career ladder at all. He starts as a professor in early American history and expects to end his career as a professor in early American History. Once tenured, Smith can work for promotions to associate and then full professor, but these changes in rank do not fundamentally affect the content of his work. What is unique about the academic job market is the narrowness and specific nature of the job assignment and the lack of a career ladder (McPherson and Winston, p. 115). Since there is no career ladder for professors analogous to the career ladders in many corporate internal markets, it is not surprising that vastly different systems of evaluation have evolved in the two spheres. Because Smith does not move up a hierarchical career ladder like many corporate workers, there is less reason to put him through periodic evaluations.

Summative Post-Tenure Reviews make Evaluations less Effective 
When peers and administrators know that they will have other chances to remove Smith after he is tenured, there will not be a strong incentive to monitor closely and to evaluate critically during the probationary pre-tenure years. If Smith does not show great promise early, the university may not be as pressed to go through the uncomfortable process of denying tenure. This natural tendency to procrastinate uncomfortable personnel decisions could have the perverse result of increasing "deadwood" rather than "weeding it out." A developmental post-tenure review program would not have this perverse effect because "dismissal" is not a possible outcome of the review process.

In addition, implementing a summative post-tenure review program could actually decrease the accuracy of personnel evaluations. Because of the highly specialized nature of academic jobs, university administrations have ceded much authority over the evaluation process to faculty members. Colleagues in the history department are certainly in a better position to evaluate Smith than administrators who have little in-depth knowledge of the history discipline. Therefore, committees of peers play an important role in hiring and tenure decisions. Faculty members take peer review seriously. They want high quality peers because their own productivity depends on collaboration with colleagues and the overall reputation of their department. Consequently, they invest quite a lot of energy into the evaluation process. They hire the best, and they only grant tenure to those with a proven record of accomplishment and exceptional promise.

However, the dynamic will change with the introduction of a periodic summative post-tenure review system. Under periodic summative review by peers, the evaluator in one review may become the person under review in the next. This introduces an unfortunate game. Jones may be reluctant to give Smith a negative evaluation knowing that Smith is likely to be evaluating Jones in the future. A predictable result is that summative post-tenure reviews conducted by peers become perfunctory exercises that seldom result in constructive criticism or dismissal. McPherson and Schapiro (1999) make a similar point:

...delegating authority to faculty over certain key decisions may not work well unless those faculty have some assurance that their own positions won't be threatened by offering honest judgments. It will be hard to get faculty members to advocate hiring highly talented faculty members, or to be good mentors for them, if those new hires may turn into competitors for their own jobs. This is a case of ... impacted information. In the absence of tenure, the relative authority of administrators in making appointment and promotion decisions would increase, because faculty recommendations would have reduced credibility" (P. 94).

In short, periodic summative post-tenure review does not appear to be well suited to the academic arena. However, developmental post-tenure review programs, like the one recently adopted at Illinois Wesleyan University, do not suffer these shortcomings. In fact, they may even increase faculty motivation.

\section{Developmental Post-Tenure Review Plans can Increase Motivation}

What motivates tenured faculty? Extensive research into this question reveals that faculty are driven by a relatively small number of motives: autonomy, community, recognition, and efficacy. (Wergin, 2001) Other studies (e.g. Blackburn and Lawrence, 1995) identify longer lists, however, these four seem to be widely accepted.

Autonomy is an important motivator of faculty performance. Our Professor Smith enjoys autonomy in pursuing his own research interests wherever they may take him. In addition, he values being able to take risks by developing new pedagogies to use in the classroom. This type of autonomy is closely related to academic freedom. While summative post tenure review systems threaten academic freedom, developmental plans like the one adopted at Illinois Wesleyan University (IWU) provides faculty members with the freedom to pursue their own interests without risk of dismissal or other penalties. For example, Smith creates his own development plan and is guaranteed resource support, even for unconventional plans.

Programs that create a sense of community motivate faculty members. Professor Smith, for example, wants to feel part of the academic community where he is nurtured and has an important role. The IWU plan creates a stronger academic community through the nurturing work of the peer review committees. A summative review can create a competitive evaluative environment that breaks down sense of community. On the other hand, a deve- 
lopmental review like the IWU plan brings colleagues together to help each other develop professionally, thus creating a stronger sense of community.

Recognition motivates. Wergin explains that "People everywhere want to feel valued, to know that others see their work as worthwhile. Faculty members are no different. We need evidence that someone's paying attention."(p. 52) IWU's developmental post tenure review program recognizes the importance of every faculty member under review. For example, Professor Smith's worth to the institution is recognized through the constructive inputs and hours of time donated to the review process by his peers. The tailored resource award is further recognition that Smith's continued association with the university is valued.

Finally, efficacy motivates faculty members. By being developmental rather than summative, the IWU plan helps faculty members to become more productive. For example, if Professor Smith is discouraged by his teaching evaluations, peers can help him identify areas where he can improve, such as developing new pedagogies. Smith may choose to include these new ideas in his development plan. With the resources provided by the university to develop it, his teaching should improve, thus increasing his feelings of efficacy and increasing his overall motivation.

\section{Conclusion}

We believe that a carefully designed developmental post-tenure review program can be a valuable supplement to personnel policies already in place at universities. Reflective evaluation of past performance and planning for professional development with a small group of peers can be a rejuvenating experience for senior faculty members. In addition, making professional development resources available to faculty members who complete reviews provides additional motivation.

Developmental post-tenure review programs have the potential to motivate faculty by giving them a high degree of autonomy and increase their sense of community as they interact with peers in a positive unthreatening environment. In addition, faculty members should feel motivated by the fact that their work is recognized as having value to the institution.

The "right" post-tenure review plan for any given university, of course, will depend upon campus culture and the existing personnel policies and professional development programs. However, we believe that a summative program that can lead to termination or other negative results for the person under review is not a good personnel policy for any university. These programs threaten academic freedom, decrease collegiality and do not motivate faculty. Furthermore, they may have unanticipated adverse effects on economic efficiency by reducing incentives for universities to monitor untenured faculty members and to devote energy to making the tough "up or out" tenure choices after the probationary period. It is far better to distance post-tenure review from the normal supervisory structure and give it a distinctly developmental focus.

\section{References:}

1. Blackburn, R. T., and Lawrence J. H. (1995). Faculty at Work: Motivation, Expectation, and Satisfaction. Baltimore, Maryland: The Johns Hopkins University Press.

2. $\quad$ Chait, R. P., and Ford A.T. (1982). Beyond Traditional Tenure. San Francisco, CA: Jossey-Bass Inc.

3. Illinois Wesleyan University Post-tenure Review Task Force. (2001). Illinois Wesleyan University PostTenure Review Program. Unpublished Task Force Report. Illinois Wesleyan University. Bloomington, IL.

4. Licata, C.M., and Morreale, J.C. (1997). Post-Tenure Review: Policies, Practices, and Precautions. Working Paper Series, Inquiry \#12. Washington, D.C.: American Association for Higher Education.

5. Machlup, F. (1996). In Defense of Academic Tenure. In M.W. Finkin (Ed.), The Case for Tenure. Ithaca, NY: Cornell University Press, 9 - 26. Reprinted from AAUP Bulletin 50, summer, 1964, 112-24.

6. McPherson, M. S. and Schapiro, O. (1999). Tenure Issues in Higher Education. Journal of Economic Perspectives. 13 (1), pp. 85-98.

7. McPherson, M. S., and Winston, G. C. (1993). The Economics of Academic Tenure: A Relational Perspec- 
tive. In M.O. Schapiro and G.C. Winston (Eds.), Paying the Piper: Productivity, Incentives, and Financing in U.S. Higher Education (Chapter 5). Ann Arbor: University of Michigan Press.

8. Osterman, P. (1984). Introduction: The Nature and Importance of Internal Labor Markets. In P. Osterman (Ed.), Internal Labor Markets. Cambridge, Mass: MIT Press.

9. Trower, C. (1999). The Trouble with Tenure. National Forum. 79 (1), 24-29.

10. Wergin, J. F. (2001). "Beyond Carrots: What Really Motivates faculty," Liberal Education. 87 (1), 50-53.

Notes

Notes 
